\title{
Social Media Research from Affordance Perspective
}

Yuan Sun*

School of Business Administration, Zhejiang Gongshang University, Hangzhou 310018, People's Republic of China

"Corresponding author: Yuan Sun, School of Business Administration, Zhejiang Gongshang University, Hangzhou 310018, China, Tel: +86- 0571-28008018, E-mail: zorrnsun@163.com

Received date: Jun 28, 2014; Accepted date: July 14, 2014; Published date: July 24, 2014

Copyright: (c) 2014 Yuan Sun. This is an open-access article distributed under the terms of the Creative Commons Attribution License, which permits unrestricted use, distribution, and reproduction in any medium, provided the original author and source are credited.

\section{Short Communication}

Nowadays, social media such as blogs, microblogs, wikis, social networking sites, or social tagging, has been rapid proliferated and widespread adopted in people's daily life and work. Recently, some researchers have used affordance perspective to investigate the social media itself. For example, Boyd [1] pointed out that networked technologies introduce new affordances for amplifying, recording, and spreading information and social acts. And she identified persistence, replicability, scalability and searchability as four key affordances that emerge out of the properties of social network sites. Treem and Leonardi [2] reviewed previous studies of social media usage in organizations and uncovered four relatively consistent affordances enabled by these new technologies, including visibility, persistence, editability, and association. In addition, Mesgari and Faraj [3] focused on Wikipedia as a case and empirically identify and define six affordances as follows: contribution affordance, control affordance, management affordance, collaboration affordance, self-presentation affordance and broadcasting affordance. Current studies about social media using affordance perspective demonstrated the theoretical and practical value of identifying the affordances of social media. While current literature has not fully understood the affordance of the social media and hence presents different result. Hence, I suggest future studies can focus attention not only on any particular social media technology, but also on a cluster of social media using an affordance approach through both theoretical analysis and empirical validation to fully open the complex nature of the social media.

\section{Acknowledgements}

This research is sponsored by National Natural Science Foundation of China (71302034), Specialized Research Fund for the Doctoral Program of Higher Education (20123326120005), Qianjiang talent Grant in Zhejiang Province (QJC1202013), and the China Postdoctoral Science Foundation (2011M500105, 2012T50560).

\section{References}

1. Boyd DM (2010) Social Network Sites as Networked Publics: Affordances, Dynamics and Implications, In: Networked Self: Identity, Community, and Culture on Social Network Sites, Z. Papacharissi (ed.). New York, NY: Routledge. 39-58.

2. Treem J, Leonardi P (2012) Social Media Use in Organizations: Exploring the Affordances of Visibility, Editability, Persistence, and Association, Communication Yearbook, 36:143-189.

3. Mesgari M, Faraj S (2012) Technology Affordances: The Case of Wikipedia, Eighteenth Americas Conference on Information Systems, Seattle, Washington. 1-9. 